\title{
Avaliação de metodologias utilizadas em estudos morfométricos de bacias hidrográficas
}

Lucas Lima Moreira ${ }^{1}$

Juan Carlos Valdés Serra²

\section{Resumo}

Diante da existência e disponibilidade de uma grande quantidade de trabalhos que abrangem a análise morfométrica de bacias hidrográficas, é possível obter diferentes métodos para a realização desse tipo de análise. 0 objetivo deste trabalho foi realizar um levantamento de metodologias que vêm sendo utilizadas na realização de análises morfométricas de bacias hidrográficas, priorizando os parâmetros e as técnicas de obtenção e medição utilizados. Foi realizada uma busca em portais científicos como Google Acadêmico e Scielo e, posteriormente, uma seleção de alguns trabalhos científicos de análises morfométricas. Eles foram analisados e comparados quanto aos métodos utilizados, considerando três critérios: dados, softwares e parâmetros utilizados. Todos os trabalhos analisados utilizaram-se de métodos diferentes, principalmente softwares e parâmetros morfométricos, mas puderam alcançar interpretações e respostas comuns para esse tipo de estudo, de forma que a diversidade de procedimentos observados torna a sua realização ainda mais prática e simples.

Palavras-chave: Análise morfométrica. Sistema de Informações Geográficas. Parâmetros morfométricos.

\section{Introdução}

Santana (2003) conceitua bacia hidrográfica como uma área geográfica natural, delimitada pelos pontos mais altos do relevo, possibilitando que a água proveniente das chuvas seja drenada superficialmente por um curso d'água principal até sua saída da bacia, no local mais baixo do relevo, que corresponde à foz desse curso d'água.

Diante da importância das bacias hidrográficas como provedoras de água aos mais diversos usos e como unidades de planejamento ambiental e gestão dos recursos hídricos, estudos e análises que as possuem como objeto são cada vez mais necessários (TUCCI, 2002).

Utilizar a bacia hidrográfica como unidade de planejamento e gestão possibilita uma melhor leitura do quadro de potencialidades e fragilidades de uma paisagem por meio do diagnóstico ambiental (RUFO; CRISTO, 2014).

A bacia de drenagem permite o entendimento da ação dos processos hidrológicos e geomorfológicos e das ligações espaciais entre áreas distintas, que podem afetar tanto o planejamento local quanto o planejamento regional (SANTANA, 2003).

Ainda segundo Rufo e Cristo (2014), a quantidade e a qualidade de água disponível podem ser modificadas por ações antrópicas; por isso, a importância de se estudar uma bacia hidrográfica, para conhecer melhor o ciclo da água e sua importância para a sociedade.

1 Universidade Federal do Tocantins, acadêmico. Palmas, Tocantins, Brasil. lucas.Im@hotmail.com. Avenida NS 15, 109 Norte - Plano Diretor Norte - Palmas (TO), 77001-090.

2 Universidade Federal do Tocantins, professor-doutor associado II .Palmas, Tocantins, Brasil. juancs@uft.edu.br. Avenida NS 15, 109 Norte - Plano Diretor Norte - Palmas (TO), 77001-090. 
O método de análise morfométrica é utilizado em estudos relacionados às interações entre processos quantitativos (SILVA; SILVA; SANTOS, 2014). A morfometria de uma bacia hidrográfica é uma ferramenta essencial de diagnóstico da suscetibilidade à degradação ambiental, retratando a disposição, o tamanho e a forma do percurso de cada segmento de rio e a densidade e o modo de distribuição de toda a rede de drenagem do terreno (STRAHLER, 1957; FRANÇA, 1968 apud ZANATA et al., 2011).

De acordo com Teodoro et al. (2007), a caracterização morfométrica de uma bacia hidrográfica é um dos primeiros e mais comuns procedimentos executados em análises hidrológicas ou ambientais e tem como objetivo elucidar as várias questões relacionadas com o entendimento da dinâmica ambiental local e regional.

Para melhor avaliar os fenômenos hidrológicos críticos, que envolvem as secas e as inundações, um monitoramento contínuo dos recursos hídricos é fundamental. Com a adequada avaliação dos recursos hídricos, utilizando o monitoramento dos dados relativos a uma microbacia, por exemplo, pode-se propor uma adequação da ocupação do solo em relação ao seu potencial e de suas limitações, tornando possível um manejo racional e equilibrado com a natureza, contribuindo com a sustentabilidade (CAMPOS et al., 2015).

Muitos parâmetros podem ser determinados em uma bacia hidrográfica, tais como: tamanho; elevação máxima, mínima e média; distribuição das elevações (cotas); aspecto; orientação, perímetro, forma e rede de drenagem que, juntamente com outras propriedades, devem ser determinadas no terreno e são parâmetros físicos de muita utilidade na avaliação das características hidrológicas, como precipitação e escoamento. O tamanho e os limites da bacia são importantes para determinar parâmetros do recurso água, por exemplo, rendimento total anual e potencial de enchente para identificar a propriedade da terra sendo manejada e para avaliar como, quando e onde aplicar medidas de manejo que controlem a qualidade de água, a quantidade ou o regime (SANTANA, 2003).

Georgin, Oliveira e Rosa (2015) analisaram e compararam a caracterização morfométrica das bacias hidrográficas do Alto Jacuí e Vacacaí, no Estado do Rio Grande do Sul, e relacionaram essa caracterização com possíveis ocorrências de cheias. Para tanto, a partir do Modelo Digital do Terreno oriundo da Missão Topográfica Radar Shuttle e shapefiles das bacias hidrográficas do terreno, foram calculados os parâmetros morfométricos para o estudo do comportamento hidrológico da bacia. As bacias hidrográficas do Alto Jacuí e Vacacaí apresentaram perfil alongado e, por meio do coeficiente de compacidade, o fator de forma e o índice de circularidade indicaram que são pouco susceptíveis a enchentes. A bacia hidrográfica possui forma alongada, amenizando a influência da intensidade de chuvas sobre a bacia.

Existem inúmeros trabalhos com bacias hidrográficas, por exemplo, Collares (2000), Alves e Castro (2003), Pissarra, Politano e Ferraudo (2004), Tonello et. al (2006), Cardoso et. al (2005). A grande maioria deles inclui a análise morfométrica das bacias. Porém, quase inexistem trabalhos que comparam ou analisam as metodologias ou procedimentos metodológicos que os autores vêm utilizando na realização desses estudos, o que seria importante, visto que há divergências metodológicas entre eles.

O objetivo deste trabalho é, portanto, realizar um levantamento de metodologias utilizadas na realização de análises morfométricas de bacias hidrográficas, priorizando os parâmetros e as técnicas de obtenção e medição utilizados. 


\section{Material e métodos}

Para o levantamento das metodologias utilizadas em estudos morfométricos de bacias hidrográficas foi realizada uma busca bibliográfica de publicações a respeito do tema. Essas publicações foram selecionadas de forma aleatória, até um número máximo total de dez, e foram avaliadas, de acordo com o conteúdo técnico e científico, semelhante ao que fizeram Machado et al. (2011).

Os trabalhos em que a qualidade não foi considerada satisfatória, ou que se apresentaram com metodologias semelhantes ou repetidas, foram descartados, até a seleção final de cinco trabalhos que apresentassem métodos diferentes. Essa avaliação deu-se segundo a observância de critérios específicos, tais como a clareza com relação aos objetivos apresentados, consistência nas discussões e resultados e, principalmente, relevância conceitual ou metodológica.

Após a definição dos trabalhos, a leitura e análise da metodologia empregada em cada um deles foi novamente realizada, de forma que se obtiveram as particularidades de cada uma, sendo possível, assim, a elaboração de um comparativo entre elas, no que diz respeito aos parâmetros e técnicas de obtenção e medição que foram utilizados, conforme retrata o Quadro 1.

Quadro 1. Critérios de avaliação metodológica

\begin{tabular}{|l|c|}
\hline \multirow{4}{*}{ Critérios a serem avaliados } & Dados utilizados \\
\cline { 2 - 2 } & Softwares, SIGs \\
\cline { 2 - 2 } & Parâmetros morfométricos \\
\hline
\end{tabular}

Fonte: Elaboração dos autores

\section{Resultados e discussão}

Christofoletti (1980), citado em quase todos os trabalhos desta temática, sugere que os índices e os parâmetros do estudo analítico sejam abordados em hierarquia fluvial, análise areal, análise linear e análise hipsométrica, conforme Quadro 2. 
Quadro 2. Metodologia de Christofoletti (1980)

\begin{tabular}{|c|c|}
\hline Hierarquia fluvial & $\begin{array}{l}\text { 1. Ordem da bacia } \\
\text { 2. Magnitude }\end{array}$ \\
\hline $\begin{array}{l}\text { Análise linear (rede } \\
\text { hidrográfica) }\end{array}$ & $\begin{array}{l}\text { 3. Relação de bifurcação } \\
\text { 4. Relação entre o comprimento médio dos canais de cada ordem } \\
\text { 5. Relação entre o índice do comprimento médio dos canais e o índice de bifurcação } \\
\text { 6. Comprimento do rio principal } \\
\text { 7. Extensão do percurso superficial } \\
\text { 8. Relação do equivalente vectorial } \\
\text { 9. Gradiente dos canais (relação entre os gradientes) }\end{array}$ \\
\hline $\begin{array}{l}\text { Análise areal } \\
\text { (medições } \\
\text { planimétricas) }\end{array}$ & $\begin{array}{l}\text { 10. Área da bacia } \\
\text { 11. Comprimento da bacia } \\
\text { 12. Relação entre o comprimento do rio principal e a área da bacia (comprimento } \\
\text { geométrico do curso de água principal) } \\
\text { 13. Forma da bacia } \\
\text { a. Índice de circularidade (MILLER, 1953). } \\
\text { b. Índice de forma (LEE e SALLE, 1970). } \\
\text { c. Índice entre o comprimento e a área da bacia } \\
\text { 14. Densidade de rios } \\
\text { 15. Densidade de drenagem } \\
\text { 16. Densidade de segmentos da bacia } \\
\text { 17. Relação entre as áreas das bacias } \\
\text { 18. Coeficiente de manutenção }\end{array}$ \\
\hline Análise hipsométrica & $\begin{array}{l}\text { 19. Curva hipsométrica } \\
\text { 20. Coeficiente de massividade e o coeficiente orográfico } \\
\text { 21. Amplitude altimétrica máxima da bacia } \\
\text { 22. Relação de relevo } \\
\text { 23. Índice de rugosidade }\end{array}$ \\
\hline
\end{tabular}

Fonte: Christofoletti (1980)

A hierarquia fluvial estabelece a classificação de determinado curso d'água no conjunto total da bacia, determinando a ordem de cada canal e consequentemente da bacia. Esse parâmetro revela a capacidade de drenagem e de transporte de sedimentos da bacia. Análises areais são índices nos quais intervêm medições planimétricas e medições lineares. Incluem índices a respeito do espaço da bacia, como sua área, comprimento, forma, densidade de drenagem e coeficiente de manutenção. A partir dessa análise, pode-se determinar o grau de susceptibilidade da bacia a enchentes, por exemplo.

A análise linear abrange índices e relações a respeito dos canais de escoamento, que permitem obter a declividade dos canais, entre outros. Abrange comprimento do rio principal e gradiente de canais.

Análise hipsométrica estuda as inter-relações existentes em uma unidade horizontal de espaço quanto a sua distribuição em relação às faixas altitudinais, compreende relação de relevo e índice de rugosidade, permitindo obter a declividade da bacia, que pode revelar a intensidade do risco da bacia a processos erosivos (CHRISTOFOLETTI, 1980).

Observa-se que a metodologia proposta por Christofoletti (1980) inclui 23 parâmetros a serem obtidos da bacia hidrográfica. O autor discute na sua proposta como obter os dados de cursos fluviais, citando o uso de mapas, fotografias aéreas ou no terreno e uso do planímetro, papel milimetrado, pesagem do papel uniforme devidamente recortado ou técnicas mais sofisticadas, como uso do computador para o cálculo da área da bacia.

Santos e Morais (2012) analisaram a morfometria da bacia hidrográfica do Rio Lago Verde em Lagoa da Confusão (TO), com o fim de obter a compartimentação do relevo da região. Com a aplicação 
dos parâmetros, foi possível traçar uma chave interpretativa da morfogênese e morfodinâmica da região da Lagoa da Confusão, tendo a bacia hidrográfica como unidade de referência para o planejamento e investigação geomorfológica, por meio de investigações quantitativas dos componentes naturais.

Os autores utilizaram o Spring 1.7 para armazenamento e processamento dos dados (vetoriais, Modelo Numérico do Terreno, raster) e um banco de dados para geração de cartas e mapas temáticos foi construído. Para o georreferenciamento e adequação dos dados para projeção e datum do projeto criado, foi utilizado o software Global Mapper 12.01. Quatro cartas topográficas na escala de 1:100.000 produzidas pelo IBGE foram utilizadas para a obtenção da rede de drenagem. As redes de drenagens digitalizadas foram transpostas e atualizadas por meio da vetorização e hierarquização sobre a imagem do satélite Resourcesat, obtendo, assim, uma rede de drenagem atualizada. Com os dados do TOPODATA, foram feitos os processamentos de investigação topográfica, como a altimetria e a declividade, auxiliando na análise hipsométrica da bacia (SANTOS; MORAIS, 2012).

Santos e Morais (2012) selecionaram para análise os parâmetros Densidade de drenagem, Densidade hidrográfica, Índice de sinuosidade, Coeficiente de manutenção, Gradiente de canais, Índice de circularidade e Relação de relevo, que foram definidos considerando os trabalhos de Christofoletti (1969, 1980), Lana et al. (2001) e Alves e Castro (2003), conforme Quadro 3.

Quadro 3. Metodologia de Santos e Morais (2012)

\begin{tabular}{|l|l|}
\hline Dados utilizados & $\begin{array}{l}\text { - Cartas topográficas 1:100.000 IBGE } \\
\text { - Imagem de Satélite Resourcesat } \\
\text { - Dados TOPODATA }\end{array}$ \\
\hline Softwares, SIGs & $\begin{array}{l}\text { - Spring } 1.7 \\
\text { - Global Mapper } 12.01\end{array}$ \\
\hline \multirow{3}{*}{ Parâmetros } & $\begin{array}{l}\text { 1. Densidade de drenagem } \\
\text { 2. Densidade hidrográfica } \\
\text { 3. Coeficiente de manutenção } \\
\text { 4. Relação de relevo }\end{array}$ \\
& 5. Gradiente de canais \\
& 6. Índice de circularidade \\
& 7. Índice de sinuosidade \\
\hline
\end{tabular}

Fonte: Adaptado de Santos e Morais (2012)

Observa-se que os autores utilizaram apenas sete parâmetros para o estudo da bacia e concluíram que o arcabouço geológico da região é constituído por rochas sedimentares, que influenciam diretamente a forma da bacia hidrográfica. Concluíram também que a bacia possui baixa declividade, propiciando inundações periódicas (SANTOS; MORAIS, 2012).

Os autores foram simplistas em suas conclusões e poderiam ter explorado mais as interpretações e suposições que os parâmetros permitiam ou, até mesmo, terem utilizado mais parâmetros, de forma a enriquecer o estudo. Poderiam também ter proposto medidas para redução dos efeitos das inundações periódicas.

Zanata et al. (2011), no intuito de verificar a influência da escala na análise física de bacias hidrográficas, utilizaram o método da análise morfométrica visando aos dados quantitativos e, com isso, diferenciar áreas homogêneas dentro dessa unidade territorial. Entre as variáveis estudadas estão as dimensionais, as do padrão de drenagem e as do relevo. A área de estudo foi a microbacia hidrográfica do Córrego da Cachoeira. As bases cartográficas na escala 1:50.000 (INSTITUTO BRASILEIRO DE 
GEOGRAFIA E ESTATÍSTICA - IBGE) e 1:10000 (INSTITUTO GEOGRÁFICO E CARTOGRÁFICO - IGC) foram utilizadas para a hierarquização da rede de drenagem e para a análise morfométrica.

Para a análise morfométrica, os autores usaram as bases cartográficas do IBGE, na Escala 1:50.000, e do IGC, Escala 1:10.000. Na vetorização dos dados referentes à conformação geomorfológica da rede de drenagem e respectivas sub-bacias de $1^{a}, 2^{a}, 3^{a}$ e $4^{a}$ ordens foi utilizado o pacote computacional AutoCADMap 2008, gerando um banco de dados com as medidas das características dimensionais, do padrão de drenagem e do relevo, com metodologias utilizadas por Arraes et al. (2010), Rodrigues, Pissarra e Campo (2008), Teodoro et al. (2007) e Pissarra et al. (2004).

O Quadro 4 mostra as variáveis calculadas no trabalho dos autores. A classificação da rede de drenagem e as microbacias hidrográficas foram hierarquizadas nas diferentes escalas, de acordo com o sistema de Horton (1945). Para cada base cartográfica e para a referência terrestre, houve a reclassificação das hierarquias fluviais. As características físicas foram analisadas para as diferentes escalas e para a referência terrestre (ZANATA et al., 2011).

Quadro 4. Metodologia de Zanata et al. (2011)

\begin{tabular}{|c|c|}
\hline Dados utilizados & $\begin{array}{l}\text { - Bases cartográficas IBGE, na Escala 1:50.000 } \\
\text { - Base cartográfica IGC, Escala 1:10.000 }\end{array}$ \\
\hline Softwares, SIGs & - AutoCADMap 2008 \\
\hline \multicolumn{2}{|r|}{ Parâmetros } \\
\hline Características dimensionais & $\begin{array}{l}\text { 1. Área } \\
\text { 2. Perímetro } \\
\text { 3. Comprimento } \\
\text { 4. Largura } \\
\text { 5. Comprimento da rede de drenagem } \\
\text { 6. Fator de forma } \\
\text { 7. Coeficiente de compacidade } \\
\text { 8. Índice de circularidade }\end{array}$ \\
\hline $\begin{array}{l}\text { Características do padrão de } \\
\text { drenagem }\end{array}$ & $\begin{array}{l}\text { 9. Densidade de drenagem } \\
\text { 10. Frequência dos rios } \\
\text { 11. Razão de textura } \\
\text { 12. Extensão de percurso superficial } \\
\text { 13. Coeficiente de Manutenção } \\
\text { 14. Razão de bifurcação }\end{array}$ \\
\hline $\begin{array}{l}\text { Característica do padrão do } \\
\text { relevo }\end{array}$ & $\begin{array}{l}\text { 15. Amplitude altimétrica } \\
\text { 16. Razão de relevo } \\
\text { 17. Razão de relevo relativo }\end{array}$ \\
\hline
\end{tabular}

Fonte: Adaptado de Zanata et al. (2011)

Os autores concluíram que uma maior escala das bases cartográficas e uma maior referência terrestre das informações cartográficas alteram o número de compartimentos hidrológicos e aumentam o comprimento da rede de drenagem, refletindo em pequenas variações nos valores dos parâmetros físicos analisados. O trabalho de campo complementou a informação da cartografia estudada com maior detalhamento sobre nascentes e córregos intermitentes e a morfometria indicou que a área tem relação positiva entre infiltração e deflúvio, com menor suscetibilidade à erosão e à degradação ambiental (ZANATA et al., 2011). 
Em Coutinho (2011), as bases de dados utilizadas foram curvas de nível digitalizadas e a hidrografia mapeada da bacia. Em ambiente de Sistema de Informações Geográficas, foram calculados vários índices morfométricos, relacionados à geometria, hidrografia e topografia da bacia hidrográfica, conforme Quadro 5.

Quadro 5. Metodologia segundo Coutinho et al. (2011)

\begin{tabular}{|c|c|}
\hline Dados & $\begin{array}{l}\text { - Curvas de níveis IBGE } \\
\text { - Carta digital (IBGE) }\end{array}$ \\
\hline Softwares, SIGs & - ArcGIS 9.3 \\
\hline \multicolumn{2}{|r|}{ Parâmetros } \\
\hline Características geométricas & $\begin{array}{l}\text { 1. Área de drenagem } \\
\text { 2. Perímetro da bacia } \\
\text { 3. Coeficiente de compacidade } \\
\text { 4. Fator de forma } \\
\text { 5. Razão de elongação } \\
\text { 6. Índice de circularidade }\end{array}$ \\
\hline Características da hidrografia & $\begin{array}{l}\text { 7. Ordem dos canais por hierarquia segundo Strahler (1957) } \\
\text { 8. Densidade de drenagem } \\
\text { 9. Densidade hidrográfica } \\
\text { 10. Sinuosidade do curso principal } \\
\text { 11. Índice de sinuosidade } \\
\text { 12. Perfil longitudinal } \\
\text { 13. Declividade de álveo }\end{array}$ \\
\hline Características do relevo & $\begin{array}{l}\text { 14. Altitude mínima, média e máxima. } \\
\text { 15. Declividade mínima, média e máxima. } \\
\text { 16. Índice de rugosidade } \\
\text { 17. Razão de relevo }\end{array}$ \\
\hline
\end{tabular}

Fonte: Coutinho et al. (2011)

Os procedimentos e métodos de geoprocessamento foram realizados no software ArcGIS 9.3. A base cartográfica de hidrografia e altimetria foi uma carta digital, disponibilizada pelo Instituto Brasileiro de Geografia e Estatística (IBGE) (COUTINHO et al., 2011).

As curvas de nível originárias da base cartográfica do Instituto Brasileiro de Geografia e Estatística (IBGE) foram interpoladas por meio de ferramentas do ArcGIS, utilizando, como suporte, a hidrografia mapeada, conforme indicação de Coutinho (2010). Esse procedimento originou um Modelo Digital de Elevação (MDE) com as depressões do terreno corrigidas. A delimitação da Bacia Hidrográfica do Rio da Prata foi realizada usando o MDE gerado, em ambiente SIG, de forma automática, utilizando os procedimentos apresentados por Medeiros et al. (2009, apud COUTINHO et al., 2011).

A determinação da área de drenagem da bacia, dos perímetros e comprimentos foi realizada empregando-se rotinas específicas do aplicativo computacional ArcGIS 9.3 (COUTINHO et al., 2011).

Com base nos dados encontrados, os autores concluíram que a bacia hidrográfica do Rio da Prata apresenta índices morfométricos de poucas tendências a enchentes, desconsiderando ocorrências anormais de precipitação (COUTINHO et al., 2011). 
Campos et al. (2015) estudaram a aplicação de geoprocessamento na caracterização morfométrica da microbacia do Ribeirão Descalvado - Botucatu (SP), por meio de Sistema de Informação Geográfica, visando à preservação, racionalização do seu uso e recuperação ambiental.

Na caracterização morfométrica da área, Campos et al. (2015) utilizaram a carta planialtimétrica do IBGE, em escala 1:50.000, com curvas de nível de 20 em 20 metros, para obtenção da rede de drenagem e da planialtimetria. Utilizaram também fotografias aéreas coloridas, em escala nominal aproximada 1:30.000, para atualização da rede de drenagem e um curvímetro digital para avaliação da rede drenagem.

Campos et al (2015) utilizaram o Idrisi Selva para vetorização das curvas de nível, do divisor de águas, da rede de drenagem e para elaboração da análise morfométrica e hierarquia dos canais.

Os parâmetros foram determinados a partir da metodologia desenvolvida por Christofoletti (1969), bem como por Almeida (2007) e Oliveira e Ferreira (2001), conforme o Quadro 6.

Quadro 6. Metodologia segundo Campos et al. (2015)

\begin{tabular}{|c|c|}
\hline Dados/Dispositivos & $\begin{array}{l}\text { - Carta planialtimétrica IBGE (1969) 1:50000, com curvas de nível de } 20 \text { em } \\
20 \text { metros. } \\
\text { - Fotografias aéreas coloridas, em escala nominal aproximada 1:30000 } \\
\text { - Curvímetro digital }\end{array}$ \\
\hline Softwares, SIGs & - Idrisi Selva \\
\hline \multicolumn{2}{|r|}{ Parâmetros } \\
\hline Parâmetros dimensionais & $\begin{array}{l}\text { Área }(A) \\
\text { Perímetro }(P) \\
\text { Comprimento do Rio Principal }(C) \\
\text { Comprimento da rede de drenagem total (Cr) } \\
\text { Comprimento das curvas de nível }(\mathrm{Cn})\end{array}$ \\
\hline Características do relevo & $\begin{array}{l}\text { Coeficiente de compacidade (Kc) } \\
\text { Fator forma (Ff) } \\
\text { Índice de circularidade (Ic) } \\
\text { Declividade média (D) } \\
\text { Altitude média (Hm) } \\
\text { Maior altitude (MA) } \\
\text { Menor altitude (mA) } \\
\text { Amplitude altimétrica (H) } \\
\text { Coeficiente de Rugosidade (CR) }\end{array}$ \\
\hline Padrões de drenagem & $\begin{array}{l}\text { Ordem da microbacia (W) } \\
\text { Densidade de drenagem (Dd) } \\
\text { Coeficiente de Manutenção (Cm) } \\
\text { Extensão do Percurso Superficial (Eps) } \\
\text { Gradiente de Canais (Gc) } \\
\text { Índice de Sinuosidade (Is) } \\
\text { Frequência de Rios (Fr) } \\
\text { Densidade Hidrográfica }\end{array}$ \\
\hline
\end{tabular}

Fonte: Campos et al. (2015) 
Campos et al. (2015) concluíram que:

- A partir do levantamento dos dados de morfometria, é possível afirmar que as variáveis morfométricas podem ser úteis para futuros planejamentos e gestões ambientais regionais.

- A microbacia apresentou susceptibilidade à erosão e degradação ambiental.

- O Sistema de Informações Geográficas Idrisi Selva mostrou-se excelente em viabilizar o monitoramento e a gestão dos recursos hídricos da microbacia.

Entre todos os trabalhos analisados e descritos, podem-se extrair singularidades e semelhanças quanto aos parâmetros utilizados, conforme Quadro 7.

Quadro 7. Quantidade de Parâmetros utilizados entre as metodologias

\begin{tabular}{|c|c|c|c|c|c|}
\hline \multirow{3}{*}{ Parâmetros } & $\begin{array}{c}\text { Christofoletti } \\
\text { (1980) }\end{array}$ & $\begin{array}{c}\text { Santos e Morais } \\
\text { (2012) }\end{array}$ & $\begin{array}{c}\text { Zanata et al. } \\
\text { (2011) }\end{array}$ & $\begin{array}{c}\text { Coutinho et al. } \\
\text { (2011) }\end{array}$ & $\begin{array}{c}\text { Campos et al. } \\
\text { (2015) }\end{array}$ \\
\cline { 2 - 6 } & 23 & 7 & 17 & 17 & 22 \\
\hline
\end{tabular}

Fonte: Elaboração dos autores

A quantidade de parâmetros adotada variou entre 7 e 23 e, em cada trabalho analisado, observou-se a divisão em grupos, agrupando parâmetros similares, como, por exemplo, grupo dos parâmetros que obtêm características dos canais de drenagem.

Entre os parâmetros houve divergência quanto à classificação, enquanto em um autor eles estavam inseridos no grupo pertinente ao relevo, em outro autor os mesmos parâmetros estavam inseridos no grupo das características dimensionais ou geométricas.

Apesar da diferença na quantidade de parâmetros entre os trabalhos, há aqueles que são fundamentais e fornecem informações indispensáveis ao propósito do estudo e que, portanto, dificilmente estão ausentes. São eles que fornecem informações quanto à susceptibilidade da bacia a enchentes, como índice de circularidade, conforme exemplifica o Quadro 8.

Quadro 8. Parâmetros comuns entre as metodologias analisadas

\begin{tabular}{|c|c|c|c|c|c|}
\hline \multirow{2}{*}{$\begin{array}{c}\text { Parâmetros } \\
\text { Comuns }\end{array}$} & $\begin{array}{c}\text { Christofoletti } \\
(1980)\end{array}$ & $\begin{array}{c}\text { Santos e Morais } \\
(\mathbf{2 0 1 2 )}\end{array}$ & $\begin{array}{c}\text { Zanata et al. } \\
(\mathbf{2 0 1 1 )}\end{array}$ & $\begin{array}{c}\text { Coutinho et al. } \\
(2011)\end{array}$ & $\begin{array}{c}\text { Campos et al. } \\
(\mathbf{2 0 1 5})\end{array}$ \\
\cline { 2 - 5 } & \multicolumn{5}{|c|}{ Índice de circularidade (Ic) } \\
Densidade de drenagem (Dd)
\end{tabular}

Fonte: Elaboração dos autores

0 índice de circularidade e densidade de drenagem são dois parâmetros que remetem especialmente à susceptibilidade de uma bacia a inundações e ao comportamento hidrológico das rochas, podendo inferir também o grau de intensidade antrópica na bacia. Essas são interpretações que se esperam obter a respeito de uma bacia hidrográfica em uma análise morfométrica, o que pode justificar a presença desses parâmetros em todas as metodologias.

Os softwares utilizados em cada um dos trabalhos estão abordados no Quadro 9.

Quadro 9. Softwares utilizados nas metodologias analisadas

\begin{tabular}{|c|c|c|c|c|c|}
\hline \multirow{2}{*}{$\begin{array}{c}\text { Softwares } \\
\text { utilizados }\end{array}$} & $\begin{array}{c}\text { Christofoletti } \\
(\mathbf{1 9 8 0 )}\end{array}$ & $\begin{array}{c}\text { Santos e Morais } \\
\mathbf{( 2 0 1 2 )}\end{array}$ & $\begin{array}{c}\text { Zanata et al. } \\
\mathbf{( 2 0 1 1 )}\end{array}$ & $\begin{array}{c}\text { Coutinho et al. } \\
\text { (2011) }\end{array}$ & $\begin{array}{c}\text { Campos et al. } \\
\text { (2015) }\end{array}$ \\
\cline { 2 - 6 } & --- & $\begin{array}{c}\text { Spring 1.7/ } \\
\text { Global Mapper } \\
12.01\end{array}$ & $\begin{array}{c}\text { AutoCADMap } \\
2008\end{array}$ & ArcGIS 9.3 & Idrisi Selva \\
\hline
\end{tabular}

Fonte: Elaboração dos autores 
Christofoletti (1980) não cita nenhum software ou ferramenta computacional, ele focaliza seus esforços em sugerir o conjunto de parâmetros que compõem a análise de bacias hidrográficas, enquanto os outros autores realizaram suas próprias análises e, para tanto, utilizaram-se de diferentes softwares, notando a possibilidade de trabalho em diversos ambientes e plataformas computacionais, com ferramentas e processos diferentes, mas que levam ao mesmo produto.

Quanto aos dados utilizados, percebe-se a importância da disponibilidade de cartas topográficas e imagens de satélites para a realização de estudos de bacias hidrográficas, uma vez que elas foram utilizadas em quase todos os trabalhos e são fontes de informações fundamentais para a caracterização das bacias, conforme Quadro 10.

Quadro 10. Dados utilizados

\begin{tabular}{|c|c|c|c|c|c|}
\hline \multirow{4}{*}{$\begin{array}{c}\text { Dados } \\
\text { utilizados }\end{array}$} & $\begin{array}{c}\text { Christofoletti } \\
\text { (1980) }\end{array}$ & $\begin{array}{c}\text { Santos e Morais } \\
(2012)\end{array}$ & $\begin{array}{c}\text { Zanata et al. } \\
\text { (2011) }\end{array}$ & $\begin{array}{l}\text { Coutinho et al. } \\
\text { (2011) }\end{array}$ & $\begin{array}{c}\text { Campos et al. } \\
\text { (2015) }\end{array}$ \\
\hline & Mapas & $\begin{array}{c}\text { Cartas } \\
\text { topográficas }\end{array}$ & \multirow{3}{*}{$\begin{array}{c}\text { Bases } \\
\text { Cartográficas }\end{array}$} & $\begin{array}{c}\text { Base } \\
\text { cartográfica }\end{array}$ & $\begin{array}{c}\text { Carta } \\
\text { planialtimétrica }\end{array}$ \\
\hline & \multirow{2}{*}{$\begin{array}{l}\text { Fotografias } \\
\text { aéreas ou no } \\
\text { terreno }\end{array}$} & $\begin{array}{l}\text { Imagem de } \\
\text { Satélite }\end{array}$ & & \multirow{2}{*}{$\begin{array}{c}\text { Cartas } \\
\text { topográficas }\end{array}$} & \multirow{2}{*}{$\begin{array}{c}\text { Fotografias } \\
\text { aéreas coloridas }\end{array}$} \\
\hline & & Dados SRTM & & & \\
\hline
\end{tabular}

Fonte: Elaboração dos autores

Por meio das bases e cartas cartográficas, mapas e imagens, pode-se obter o divisor de águas, extrair rede de drenagem, curvas de nível, gerar Modelos Digitais de Elevação, entre outros. Informações, bases cartográficas e imagens de satélite disponibilizadas gratuitamente por órgãos como o IBGE, o Instituto Nacional de Pesquisas Espaciais (INPE), a Empresa Brasileira de Pesquisa Agropecuária (EMBRAPA) e órgãos estaduais revelaram-se de extrema importância no desenvolvimento de trabalhos como os analisados neste estudo.

\section{Conclusão}

Os trabalhos possuem objetivos semelhantes, porém, utilizam diferentes procedimentos metodológicos, com dados, softwares e parâmetros diversos. No entanto, as interpretações e respostas esperadas e comuns para análises morfométricas de bacias são satisfatoriamente obtidas.

Pelos resultados alcançados, observou-se a possibilidade de ajustes nos métodos, por meio de combinações de dados, softwares e parâmetros, de acordo com o objetivo do trabalho. Assim, as metodologias para realização de análises morfométricas podem ser facilmente modificadas ou adaptadas, de acordo com a disponibilidade dos dados e ferramentas como Sistemas de Informações Geográficas, com exceção das definições dos parâmetros, que já estão padronizadas pela literatura.

A análise morfométrica é um estudo simples e prático, e a diversidade de metodologias disponíveis e possíveis de serem realizadas, juntamente com a grande disponibilidade de dados, softwares e referências, torna sua realização ainda mais fácil e acessível. 


\title{
Evaluation of methodologies used in morphometric studies of watersheds
}

\begin{abstract}
Due to the existence and availability of a large amount of work covering the morphometric analysis of watersheds, it is possible to obtain different methods to perform this type of analysis. The present study aimed to survey methodologies that have been used in carrying out morphometric analysis of watersheds, prioritizing the parameters, obtainment techniques and used measurement. Furthermore, a search was conducted on online portals of scientific publication, and a selection of some scientific works on morphometric analysis took place. The data were analyzed and compared according to the methods used, through three criteria: data, software and adopted parameters. All analyzed studies used different methods, mainly software and morphometric parameters, still they were able to reach common understandings and responses for this type of study; thus, the diversity of observed procedures makes their achievement even more convenient and simple.
\end{abstract}

Keywords: Morphometric analysis. Geography Information System. Morphometric parameters.

\section{Referências}

ALMEIDA, A. Q. de. Influência do desmatamento na disponibilidade hídrica da bacia hidrográfica do Córrego do Galo, Domingos Martins (ES). 2007 - 92f. Dissertação (Mestrado em Engenharia Ambiental) - Centro Tecnológico, Universidade Federal do Espírito Santo, Vitoria, 2007.

ALVES, J. M. P.; CASTRO, P. T. A. Influência de feições geológicas na morfologia da bacia do Rio Tanque (MG) baseada no estudo de parâmetros morfométricos e análise de padrões de lineamentos. Revista Brasileira de Geociências, v. 33, n. 2, p. 117-127, 2003.

ARRAES, C. L.; PISSARRA, T. C. T.; RODRIGUES, F. M.; ZANATA, M.; Campos, S. Morfometria dos compartimentos hidrológicos do município de Jaboticabal, SP. Revista Unopar Científica, Ciências Exatas e Tecnológicas, v. 9, p. 27-32, 2010.

CAMPOS, S.; FELIPE, A. C.; CAMPOS, M.; RECHE, A. M. Geoprocessamento aplicado na caracterização morfométrica da microbacia do Ribeirão Descalvado - Botucatu (SP). Irriga, Botucatu, p. 52-65, 2015.

CARDOSO, C. A.; DIAS, H. C. T.; SOARES, B. C. P.; MARTINS, S. V. Caracterização morfométrica da bacia hidrográfica do Rio Debossan, Nova Friburgo (RJ). Revista Árvore. Viçosa (MG), v. 30, n. 2, p. 241-248, 2006.

CHRISTOFOLETTI, A. Análise morfométrica das bacias hidrográficas. Notícia Geomorfologia, Campinas, v. 9, n. 18, p. 35-64, 1969.

CHRISTOFOLETTI, A. Geomorfologia. São Paulo: Edgard Blucher, 1980.

COUTINHO, L. M. Impacto das áreas de preservação permanente sobre a erosão hídrica na bacia hidrográfica do Rio da Prata, Castelo (ES). 2010. 86 f. Dissertação (Mestrado em Ciências Florestais) - Universidade Federal do Espírito Santo, 2010. 
COUTINHO, L. M.; CECÍlIO, R. A.; XAVIER, A. C.; ZANETTI, S. S.; GARCIA, G. O. Caracterização morfométrica da bacia hidrográfica do Rio da Prata, Castelo (ES). Irriga, Botucatu, v. 16, n. 4, p. 369-381, 2011.

COLLARES, E. G. Avaliação de alterações em redes de drenagem de microbacias como subsídio ao zoneamento geoambiental de bacias hidrográficas: aplicação na bacia hidrográfica do Rio Capivari (SP). 2000. Tese de Doutorado. Universidade de São Paulo, 2000.

GEORGIN, J.; OLIVEIRA, G. A.; ROSA, A. L. D. da. Estudo comparativo de índices morfométricos relacionado com cheias nas bacias hidrográficas do Alto Jacuí e Vacacaí - Vacacaí Mirim (RS). Revista Eletrônica em Gestão, Educação e Tecnologia Ambiental, Santa Maria, v. 19, n. 2, p. 1357-1364, maio, 2015.

HORTON, R. E. Erosional development of streams and their drainage basins: hidrophysical approach to quantitative morphology. Bulletin of the Geological Society of America, Colorado, v. 56, n. 3, p. 275-370, 1945.

LANA, C. E.; ALVES, J.; CASTRO, P. T. A. Análise Morfométrica da Bacia Hidrográfica do Rio Tanque, Minas Gerais, Brasil. Revista da Escola de Minas, v. 54 n. 2, 2001.

MACHADO, R. A. S.; LOBÃO, L. S. B.; VALE, R. M. C.; SOUZA, A. P. M. J. Análise morfométrica de bacias hidrográficas como suporte à definição e elaboração de indicadores para a gestão ambiental a partir do uso de geotecnologias. In: SIMPÓSIO BRASILEIRO DE SENSORIAMENTO REMOTO, 15. , 2011, Curitiba. Anais... Curitiba: Inpe, p. 1441 - 1448, 2011.

OLIVEIRA, A.; FERREIRA, E. Caracterização de sub-bacias hidrográficas. Lavras: UFLA/FAEPE, 64p., 2001.

PISSARRA, T. C. T.; POLITANO, W.; FERRAUDO, A. S. Avaliação de características morfométricas na relação solo-superfície da bacia hidrográfica do córrego Rico, Jaboticabal (SP). Revista Brasileira de Ciência do Solo, v. 28, p. 297-305, 2004.

RODRIGUES, F. M.; PISSARRA, T. C. T.; CAMPO, S. Caracterização morfométrica da microbacia hidrográfica do córrego da fazenda Glória, município de Taquaritinga, SP. Irriga, v. 13, p. 310-322, 2008.

RUFO, R. L. T.; CRISTO, S. S. V. de. Sensoriamento remoto aplicado na análise do uso e ocupação da bacia hidrográfica do Córrego Titira, Porto Nacional, Tocantins. Revista Interface (Porto Nacional), n. 7, p. 47-60, 2014.

SANTOS, D. A. R. dos; MORAIS, F. de. Análise morfométrica da bacia hidrográfica do Rio Lago Verde como subsídio à compartimentação do relevo da região de Lagoa da Confusão (TO). Revista Geonorte, Manaus, v. 3, n. 4, p. 617-629, 2012.

SANTANA, D. P. Manejo Integrado de Bacias Hidrográficas. Sete Lagoas: Embrapa, 2003.

SILVA, A. R. da; SILVA, M. F. da; SANTOS, L. C. A. dos. Caracterização morfométrica da bacia hidrográfica do Rio Cacau (MA). Revista Percurso - Nemo, Maringá, v. 6, n. 2, p. 141-153, set. 2014.

STRALHER, A. N. Quantitative analysis of watershed geomorphology. Transactions of the American Geophysical Union, New Haven, v. 38, p. 913-920, 1957. 
TEODORO, V. L. I.; TEIXEIRA, D.; COSTA, D. J. L.; FULLER, B. B. O conceito de bacia hidrográfica e a importância da caracterização morfométrica para o entendimento da dinâmica ambiental local. Revista Uniara, v. 20, p. 137-156, 2007.

TONELLO, K. C.; DIAS, H. C. T.; SOUZA, A. L. de; RIBEIRO, C. A. A. S.; LEITE, F. P. Morfometria da bacia hidrográfica da Cachoeira das Pombas, Guanhães (MG). Revista Árvore, Viçosa, v. 30, n. 5, p.849-857, out. 2006.

TUCCI, C. E. M. (Org.). Hidrologia: ciência e aplicação. 3. ed. Porto Alegre: Editora da UFRGS / Abrh, 2002.

ZANATA, M.; PISSARRA, T. C. T.; ARRAES, C. L.; RODRIGUES, F. M.; CAMPOS, S. Influência da escala na análise morfométrica de microbacias hidrográficas. Revista Brasileira de Engenharia Agrícola e Ambiental, Campina Grande, v. 15, n. 10, p. 1062-1067, 2011.

\section{Histórico editorial:}

Submetido em: 27/01/2016

Aceito em: 21/03/2016

Como citar:

$\underline{A B N T}$

MOREIRA, L. L.; SERRA, J. C. V. Avaliação de metodologias utilizadas em estudos morfométricos de bacias hidrográficas. Revista Agrogeoambiental, Pouso Alegre, v. 9, n. 1, p.101-113, jan./mar. 2017. DOI: http://dx.doi.org/10.18406/2316-1817v9n12017943

APA

MOREIRA, L. L. \& SERRA, J. C. V. (2017). Avaliação de metodologias utilizadas em estudos morfométricos de bacias hidrográficas. Revista Agrogeoambiental, 9 (1), 101-113. DOI: http://dx.doi.org/10.18406/2316-1817v9n12017943

$\underline{\text { ISO }}$

MOREIRA, L. L. e SERRA, J. C. V. Avaliação de metodologias utilizadas em estudos morfométricos de bacias hidrográficas. Revista Agrogeoambiental. 2017, vol. 9, n. 1, pp. 101-113. elSSN 2316-1817. DOI: http://dx.doi.org/10.18406/2316-1817v9n12017943

VANCOUVER

Moreira LL, Serra JCV. Avaliação de metodologias utilizadas em estudos morfométricos de bacias hidrográficas. Rev agrogeoambiental. 2017 jan/mar; 9(1): 101-113. DOI: http://dx.doi.org/10.18406/2316-1817v9n12017943 